\title{
Effect of reproductive hormones variation during menstrual cycle on hip abductor and adductor muscles performance in college students
}

\author{
Abeer M. EIDeeb ${ }^{a}$, Doaa M. Osman ${ }^{a}$, Hanaa K. Atta ${ }^{b}$, Hamada A. Hamadac
}

\author{
Department of aPhysical Therapy for Women's \\ Health, ${ }^{b}$ Basic Science, ${ }^{\mathrm{C} B i o m e c h a n i c s,}$ \\ Faculty of Physical Therapy, Cairo University, \\ Giza, Egypt \\ Correspondence to Abeer M. EIDeeb, PhD, \\ Department of Physical Therapy for Women's \\ Health, Cairo University, 7 Ahmed El-Zayat \\ Street, Bein El-Sarayat, Dokki, Giza, Egypt. \\ Tel: 00201001811588; \\ e-mail: beroeldeeb@yahoo.com \\ Received 3 December 2018 \\ Accepted 20 August 2019
}

Bulletin of Faculty of Physical Therapy 2019, 24:72-78

\begin{abstract}
Background
The hip abductors and adductors play an important role in the stability of the hip and knee joints and knee injury risk. Menstrual cycle is associated with hormones fluctuations that may affect functions of muscles and ligaments and increase the knee risk injury. However, their effect on the abductors and adductors performance is still unknown, which may be a step in developing conditioning programs to reduce injury risk.

\section{Objectives}

This study aimed to examine the effect of hormones variation during menstrual cycle on abductor and adductor muscles performance in sedentary college students.

Patients and methods

Twenty-four college students completed the study protocol. Their age and BMI ranged from 19 to 25 years and $25-29.9 \mathrm{~kg} / \mathrm{m}^{2}$, respectively. Levels of estradiol, progesterone, luteinizing hormone, and follicle-stimulating hormone were measured. Biodex system 3-isokinetic dynamometer was used to measure isokinetic parameters of hip abductor and adductor muscles including peak torque, maximum work, total work, average power, work repetition number, work fatigue percentage, angle of peak torque, acceleration time, and deceleration time. Measurements were taken during early follicular (1-3 days) and mid-luteal phases (21-23 days), which were detected using basal body temperature method.

\section{Results}

There were significant increases in estradiol $(P=0.0001)$, progesterone $(P=0.002)$, peak torque of hip abductors $(P=0.03)$ and adductors $(P=0.04)$, maximum work of hip abductors $(P=0.01)$, total work of hip abductors $(P=0.01)$ and adductors $(P=0.02)$, and average power of hip abductors $(P=0.0 .01)$ and adductors $(P=0.02)$ during the mid-luteal phase compared with the early follicular phase.

Conclusions

Abductor and adductor muscles strength changes with the surging levels of estradiol and progesterone during normal menstrual cycle that need to be considered in strengthening exercises for sedentary college students to avoid injury risk.
\end{abstract}

\section{Keywords:}

menstrual cycle, muscle performance, reproductive hormones

Bulletin of Faculty of Physical Therapy 24:72-78

(C) 2019 Bulletin of Faculty of Physical Therapy

$1110-6611$

\section{Introduction}

The menstrual cycle is characterized by fluctuations of female steroid hormone profile. There is a cyclical pattern of serum levels of estradiol, progesterone, luteinizing hormone (LH), follicle-stimulating hormone $(\mathrm{FSH})$, which are coordinated by the hypothalamus-pituitary-gonadal axis [1]. Presence of estradiol and progesterone receptors in bone, skeletal muscles, ligaments, and nervous system suggests the role of the hormonal fluctuations on the structures and functions of these tissues, as well as changes in physical performance [2].

Previous studies have reported that increased female sex hormones cause laxity of anterior cruciate ligament
(ACL) and consequent increased risk of injury [3]. Females have shown higher ACL injuries by three to six times than their male counterparts [4]. Although, most ACL injuries occur in athletic environment, nonathletic population reported injuries during daily living activities by $28.1 \%$ and recreational activities by $60.1 \%[5]$.

The effect of reproductive hormones on muscle functions in females is partly discussed in the

This is an open access journal, and articles are distributed under the terms of the Creative Commons Attribution-NonCommercial-ShareAlike 4.0 License, which allows others to remix, tweak, and build upon the work non-commercially, as long as appropriate credit is given and the new creations are licensed under the identical terms. 
literatures and showed contradictory findings. The maximum voluntary force of the adductor pollicis muscle showed an increase during the follicular phase in both trained and untrained groups [6]. Also, quadriceps and handgrip strength increased at midcycle compared with both follicular and luteal phases [7]. On contrary, another study has reported that maximal isometric quadriceps strength and handgrip strength had no differences among menstrual, late follicular, and luteal phases [8]. In addition, eccentric and concentric peak torques and total works of dominant knee muscles were not significantly different among the menstrual cycle phases [9].

Hip abductor muscles are important muscles that can affect physical performance [10]. They prevent excessive hip adduction and internal rotation during gait and multiplanar activities. Females have shown lower hip abduction torque $[11,12]$ and a higher measure of knee-valgus angle when performing dynamic tasks compared with their male counterparts $[13,14]$. Previous studies have reported an association between hip abductors strength and dynamic knee valgus alignment that increase ACL injury risk, thus recommending the importance of hip abductors strength exercises $[15,16]$. To authors' knowledge, there is no previous study that evaluates the effect of the hormones variation on hip abductor and adductor muscles performance during different menstrual cycles. Moreover, all previous studies [6-9] have focused on measuring maximum peak torque during menstrual phases without addressing other isokinetic variables, which correspond to the muscle performance [17]. Therefore, this study aimed to investigate the effect of hormones variation on isokinetic hip abductor and adductor muscles performance during early follicular phase and midluteal phase. Recording this effect may help to design appropriate exercise program for females according to their menstrual phases. It was hypothesized that there would be a difference in the hip abductor and adductor muscles performance between the early follicular and mid-luteal phases.

\section{Patients and methods \\ Patients}

Twenty-eight healthy, non-athletic, virginal females participated in this study. Their ages ranged from 19 to 25 years old and their BMI was $25-29.9 \mathrm{~kg} / \mathrm{m}^{2}$. They experienced a regular ovulatory menstrual cycles, which were confirmed by measuring their daily sublingual morning temperatures during one entire menstrual cycle prior to testing [18].
Exclusion criteria included females with nonovulatory and luteal phase deficient cycles, a history of dysmenorrhea, pelvic inflammatory diseases, myoma and tumors, pelvic infection, ovarian cyst, any gynecological diseases, lower extremity injury or surgery, cardiovascular, pulmonary, neurological or systemic conditions or females receiving contraceptives or any hormonal therapy.

The sample size was calculated according to the difference in the mean value of estradiol between early follicular phase and mid-luteal phase based on a previous study [18]. Assuming an impact size of 0.55 , $\alpha=0.05$ and power of $80 \%$, a sample size of 28 participants was required.

Each participant signed a consent form before starting this study. The assessment procedures followed were in accordance with the ethical standards of the Faculty of Physical Therapy and with the Helsinki Declaration of 1975, as revised in 2000. The Ethical Research Committee, Faculty of Physical Therapy approved the study protocol in February 2017 (No: P.T.REC/ 012/001544).

\section{Assessment procedures}

Detection of exact time of ovulation

Mercurial thermometer with scale steps of $0.05^{\circ} \mathrm{C}$ was used to record females' daily basal body temperatures (BBT) during one entire menstrual cycle prior to testing. Mercurial thermometer is a simple, noninvasive, cheap, and most frequently used method for monitoring BBT in both research and self-assessment settings. BBT is broadly used for evaluation of ovulatory function, especially for women who are reluctant or unable to use more formal and costly evaluation methods [19]. BBT was measured orally for 5 min on the morning daily for one entire cycle of each female. BBT keeps in the lower range between 97.0 and $98.08 \mathrm{~F}$ during the follicular phase and reaches its lowest point (nadir or dip) $\sim 1$ day before ovulation. It rises $0.5-1.08 \mathrm{~F}$ and plateaus throughout the luteal phase and returns to the lower range within 1-2 days before, or just at, the onset of menstrual bleeding, which indicates the first day of the menstrual cycle [19]. A biphasic temperature pattern is used as a characteristic of a normal ovulatory cycle and detects the days of the follicular and luteal phases [8]. The early follicular phase is between the first and third days of the menstrual cycle and the mid-luteal phase is between the 21st and 23rd days of the menstrual cycle [20].

\section{Hormonal analysis}

Blood samples were collected during the early follicular phase (between the first and third days of the menstrual 
cycle) and the mid-luteal phase (between the 21st and 23rd days of the menstrual cycle) [20]. Early follicular and mid-luteal phases were selected for testing because the total estradiol and progesterone concentrations are low and high, respectively, at these times. Also, estradiol is the hormone, which is the most implicated in strength regulation. In addition, measurements of estradiol, progesterone, LH, and FSH are important in monitoring of different females' conditions [21]. Blood samples were taken after $12 \mathrm{~h}$ fasting at 10.00 a.m. to avoid hormonal diurnal variation. The samples were allowed to clot in a water bath at a room temperature $37^{\circ} \mathrm{C}$. Then, the serum was separated using a centrifuge at $4000 \mathrm{rpm}$ for $15 \mathrm{~min}$ and stored at $-80^{\circ} \mathrm{C}$ till analysis. Plasma concentration of estradiol, progesterone, $\mathrm{LH}$, and FSH levels were measured using ADVIA Centaur XPT system (Bayer Corp., USA, Siemens Healthcare Diagnostics Inc., Laboratory Diagnostics 511 Benedict Avenue Tarry town, NY, USA) [22].

\section{Assessment of abductor and adductor muscles performance}

Biodex system 3-isokinetic dynamometer (Biodex Medical System, Shirley, New York, USA) was used to measure hip abductors and adductors isokinetic parameters. It is used in both clinical and research settings. It is a contemporary isokinetic dynamometer with an electrically controlled servomechanism. It consists of testing chair, dynamometer, and computer system. The testing chair is equipped with a special forward reclined sitting surface seat, adjustable straps, and knee blocks for prevention of forward sliding. A visual feedback from a computer monitor and a verbal encouragement were provided to all participants to promote maximal efforts during all trials [23]. The hip abductors and adductors isokinetic parameters were tested at one angular velocity $(60 \%)$ in the concentric mode and $30^{\circ}$ of hip abduction [24]. The isokinetic evaluation was performed from the standing position because it was the most functional position for the assessment of hip abductor/adductor muscles strength [25]. The cushion setting was in the hard position to minimize the deceleration at the end of the hip abduction range of motion that would affect torque generation during movement [26]. Each female performed three submaximal, hip abduction repetitions to get accommodated with the specificity of the Biodex speed of movement. Then, each participant performed three consecutive maximal-effort reciprocal hip abduction/adduction movement patterns with 2-min rest between each movement. The average of the isokinetic variables for the three repetitions were recorded [27]. The measured variables included abductors and adductors torque, maximum work, total work, average power, maximum work repetition number, work fatigue percentage, angle of peak torque, acceleration time, and deceleration time [17]. All measurements were taken in the early follicular and mid-luteal phases.

\section{Statistical analysis}

All statistical measures were performed using the Statistical Package for Social Science program, version 23, for Windows. Results are expressed as mean \pm SD. Shapiro-Wilk test was used to assess the normality of the data. Paired $t$ test was used to compare variables in normally distributed data, while Wilcoxon signed ranks test was used to compare variables in notnormally distributed data. The alpha level was set at 0.05 .

\section{Results}

Twenty-four participants completed the study protocol; four participants refused to complete the postassessment procedures for personal causes. The mean values of participants' age, weight, height, and BMI of participants were $22.58 \pm 1.31$ years, 65.41 $\pm 9.96 \mathrm{~kg}, \quad 162.83 \pm 4.87 \mathrm{~cm}$, and $24.57 \pm 3.32 \mathrm{~kg} / \mathrm{m}^{2}$, respectively.

Paired $t$ test revealed statistically significant increases in the estradiol $(P<0.0001)$ and progesterone $(P=0.002)$, as well as nonsignificant difference in $\mathrm{LH}(P=0.14)$ and FSH $(P=0.09)$ in the mid-luteal phase compared with the early follicular phase (Table 1). Regarding to isokinetic parameters, paired $t$ test showed statistically significant increase in peak torque of hip abductors $(P=0.03)$ and adductors $(P=0.04)$, maximum work of hip abductors $(P=0.01)$, total work of hip abductors $(P=0.01)$, and adductors $(P=0.02)$, and average power of hip abductors $(P=0.0 .01)$ and adductors $(P=0.02)$ in the mid-luteal phase compared with the early follicular

Table 1 Mean values differences for reproductive hormones during early follicular and mid-luteal phases

\begin{tabular}{lcccc}
\hline Outcomes & $\begin{array}{c}\text { Early } \\
\text { follicular } \\
\text { phase }\end{array}$ & $\begin{array}{c}\text { Mid-luteal } \\
\text { phase }\end{array}$ & $\begin{array}{c}\text { Mean } \\
\text { difference }\end{array}$ & $P$ value \\
\hline Estradiol $(\mathrm{pg} /$ & 65.26 & 161.60 & 96.29 & $<0.0001^{* *}$ \\
$\mathrm{ml})$ & \pm 14.62 & \pm 16.67 & & \\
Progesterone & $4.57 \pm 2.63$ & 9.23 & 4.66 & $0.002^{*}$ \\
$(\mathrm{ng} / \mathrm{ml})$ & & \pm 5.55 & & \\
$\mathrm{LH}(\mathrm{mlU} / \mathrm{ml})$ & $6.33 \pm 1.58$ & 5.57 & -0.76 & 0.14 \\
& & \pm 1.74 & & \\
FSH $(\mathrm{mlU} / \mathrm{ml})$ & $5.67 \pm 1.67$ & 4.82 & -0.85 & 0.09 \\
& & \pm 1.70 & & \\
\hline
\end{tabular}

$\mathrm{FSH}$, follicular-stimulating hormone; $\mathrm{LH}$, luteinizing hormone. $* P$ value less than 0.05 . $* * P$ value less than 0.01 . 
Table 2 Mean values differences for isokinetic hip abductors and adductors variables during early follicular and mid-luteal phases

\begin{tabular}{|c|c|c|c|c|}
\hline Outcomes & $\begin{array}{l}\text { Early } \\
\text { follicular } \\
\text { phase }\end{array}$ & $\begin{array}{l}\text { Mid- } \\
\text { luteal } \\
\text { phase }\end{array}$ & $\begin{array}{c}\text { Mean } \\
\text { difference }\end{array}$ & $\begin{array}{c}P \\
\text { value }\end{array}$ \\
\hline $\begin{array}{l}\text { Abductors peak torque } \\
(\mathrm{Nm})\end{array}$ & $\begin{array}{c}44.17 \\
\pm 26.30\end{array}$ & $\begin{array}{r}56.45 \\
\pm 31.02\end{array}$ & 12.28 & $0.03^{*}$ \\
\hline $\begin{array}{l}\text { Adductors peak torque } \\
(\mathrm{Nm})\end{array}$ & $\begin{array}{c}32.52 \\
\pm 24.41\end{array}$ & $\begin{array}{r}43.19 \\
\pm 29.09\end{array}$ & 10.67 & $0.04 *$ \\
\hline $\begin{array}{l}\text { Maximum abductors } \\
\text { work }(\mathrm{J})\end{array}$ & $8.63 \pm 5.50$ & $\begin{array}{l}11.81 \\
\pm 6.55\end{array}$ & 3.18 & $0.01^{*}$ \\
\hline $\begin{array}{l}\text { Maximum adductors } \\
\text { work }(\mathrm{J})\end{array}$ & $7.88 \pm 6.76$ & $\begin{array}{c}9.74 \\
\pm 6.59\end{array}$ & 1.85 & 0.13 \\
\hline $\begin{array}{l}\text { Total abductors work } \\
\text { (J) }\end{array}$ & $\begin{array}{c}32.24 \\
\pm 21.66\end{array}$ & $\begin{array}{c}47.57 \\
\pm 29.83\end{array}$ & 15.33 & $0.01^{*}$ \\
\hline $\begin{array}{l}\text { Total adductors work } \\
\text { (J) }\end{array}$ & $\begin{array}{r}28.52 \\
\pm 26.35\end{array}$ & $\begin{array}{c}39.84 \\
\pm 29.83\end{array}$ & 11.32 & $0.02^{*}$ \\
\hline $\begin{array}{l}\text { Maximum abductors } \\
\text { work repetitions } \\
\text { number }^{\mathrm{a}}\end{array}$ & $4(4)$ & $4(3)$ & 0 & 0.44 \\
\hline $\begin{array}{l}\text { Maximum abductors } \\
\text { work repetition } \\
\text { number }^{\mathrm{a}}\end{array}$ & $3(4)$ & $3(4)$ & 0 & 0.65 \\
\hline $\begin{array}{l}\text { Abductors work fatigue } \\
\text { percentage }\end{array}$ & $\begin{array}{r}28.45 \\
\pm 23.42\end{array}$ & $\begin{array}{c}24.66 \\
\pm 19.46\end{array}$ & 3.8 & 0.52 \\
\hline $\begin{array}{l}\text { Adductors work fatigue } \\
\text { percentage }\end{array}$ & $\begin{array}{c}38.31 \\
\pm 27.38\end{array}$ & $\begin{array}{c}32.34 \\
\pm 24\end{array}$ & 5.96 & 0.58 \\
\hline $\begin{array}{l}\text { Average abductors } \\
\text { power (W) }\end{array}$ & $9.92 \pm 6.30$ & $\begin{array}{l}14.38 \\
\pm 8.29\end{array}$ & 4.47 & $0.01 *$ \\
\hline $\begin{array}{l}\text { Average adductors } \\
\text { power (W) }\end{array}$ & $8.84 \pm 7.65$ & $\begin{array}{l}12.40 \\
\pm 9.11\end{array}$ & 3.56 & $0.02^{*}$ \\
\hline $\begin{array}{l}\text { Angle of abductors } \\
\text { peak torque }\left(^{\circ}\right)\end{array}$ & $\begin{array}{l}12.63 \\
\pm 4.98\end{array}$ & $\begin{array}{c}11 \\
\pm 5.54\end{array}$ & 1.62 & 0.27 \\
\hline $\begin{array}{l}\text { Angle of adductors } \\
\text { peak torque }\left(^{\circ}\right)\end{array}$ & $15.29 \pm 6.1$ & $\begin{array}{c}14.5 \\
\pm 7.22\end{array}$ & 0.79 & 0.71 \\
\hline $\begin{array}{l}\text { Abductors acceleration } \\
\text { time }(\mathrm{ms})\end{array}$ & $\begin{array}{c}100 \\
\pm 40.75\end{array}$ & $\begin{array}{c}88.33 \\
\pm 53.38\end{array}$ & -11.67 & 0.36 \\
\hline $\begin{array}{l}\text { Adductors acceleration } \\
\text { time }(\mathrm{ms})\end{array}$ & $\begin{array}{c}103.3 \\
\pm 48.24\end{array}$ & $\begin{array}{c}106.7 \\
\pm 53.78\end{array}$ & 3.33 & 0.77 \\
\hline $\begin{array}{l}\text { Abductors deceleration } \\
\text { time }(\mathrm{ms})\end{array}$ & $\begin{array}{c}176.3 \\
\pm 74.65\end{array}$ & $\begin{array}{c}180.4 \\
\pm 72.08\end{array}$ & 4.17 & 0.84 \\
\hline $\begin{array}{l}\text { Adductors deceleration } \\
\text { time (ms) }\end{array}$ & $\begin{array}{c}125 \\
\pm 73.54\end{array}$ & $\begin{array}{c}140.4 \\
\pm 67.53\end{array}$ & 15.42 & 0.49 \\
\hline
\end{tabular}

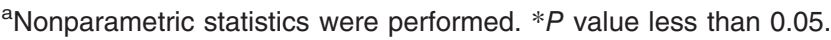
phase. However, it showed nonsignificant difference between two phases in maximum work of adductors $(P=0.13)$, work fatigue percentage of abductors $(P=0.52)$, and adductors $(P=0.58)$, angle of peak torque of abductors $(P=0.27)$ and adductors $(P=0.71)$, acceleration time of abductors $(P=0.36)$ and adductors $(P=0.77)$, and deceleration time of abductors $(P=0.84)$ and adductors $(P=0.49)$. Also, Wilcoxon signed ranks test showed nonsignificant differences in maximum work repetition number of abductors $(P=0.44)$ and adductors $(P=0.65)$ (Table 2$)$.

\section{Discussion}

The purpose of this study was to investigate the effect of sex hormone variations during the normal menstrual cycle on hip abductor and adductor muscles performance. With regards to hormonal assessment, the results have showed greater estradiol and progesterone levels in the mid-luteal phase compared with the early follicular phase.

The present findings were supported by the previous studies $[18,28]$, which have reported low levels of estradiol and progesterone during the early follicular phase, as well as increased their levels in the mid-luteal phase. The previous increase in the hormones level occurs in response to a sudden surge of $\mathrm{LH}$ to stabilize the endometrium for implantation of the fertilized egg. The hormones mean values observed in this study are in agreement with Stricker et al. [21].

The present study showed greater maximum abductors and adductors torques in the mid-luteal phase compared with the early follicular phase. Bambaeichi et al. [29] have reported the same findings in peak knee extensor torque of sedentary women. Also, Oosthuyse and Bosch [30] have demonstrated improvement of endurance performance in the mid-luteal phase compared with the early follicular phase. Moreover, Middleton and Wenger [31] found a significant enhancement in power output during 10 and 6-s maximal sprints on a cycle ergometer in the luteal phase.

However, these findings disagree with Gur [9] who mentioned no change in quadriceps and hamstrings concentric and eccentric torques in sedentary women during the follicular phase (days 1-3) compared with the luteal phase (days 19-21). Also, Janse de Jonge et al. [8] observed no change in isometric and isokinetic contractions of the quadriceps between the menstrual and luteal phases. Moreover, other researchers have reported no change in isokinetic knee extension torque [32] in moderately active college students and maximum voluntary isometric contraction of knee extension and flexion in trained women [27]. It has been reported that active women have lower estradiol level than sedentary women, therefore the acute effect of hormone fluctuations on muscle strength may not pronounce as in sedentary women [27]. In addition, the controversy of the findings between studies in sedentary women may be attributed to the variations in methods of the menstrual phase determination.

Peak torque indicates the torque generated at a single point of the entire range of motion, while maximum work corresponds to the ability of the muscle to generate torque throughout the entire range of motion [33]. Although the peak torque is the 
variable most widely used in the isokinetic measurement, a previous study recommended the use of the maximum work other than peak torque to represent the torque generation capacity [17]. In the present study, increased abductors and adductors maximum work peaks in the mid-luteal phase suggest that the mid-luteal phase is characterized by more torque generation capacity than the early follicular phase.

Hip abductors peak torque is critical for distal segments, especially knee joint kinematics and its pathologies [34,35]. Patients with low isometric hip abductors peak torque exhibited increased hip adduction angle [36] and knee abduction angle [37] during running. Previous studies have reported that insufficient muscular control by hip abductors may be associated with excessive knee valgus, tibial internal rotation, and excessive foot pronation. The previous misalignment may lead to many musculoskeletal problems such as low back pain, ankle instability [35,38-40], and patellofemoral pain syndrome [34]. That explains why hip abductors torque is considered an indicator of risk of injury in the lower limb [35]. Therefore, decreased hip abductors torque found in the follicular phase compared with the luteal phase suggests the increased risk of injury in the follicular phase in college students. These results are greatly supported by the findings of Arendt et al. [41] who have found a significant decrease in injuries during the mid-luteal phase compared with the early follicular phase. Also, Lefevre et al. [42] concluded that anterior ACL tear risk in women is 2.4-fold more frequent in the follicular and ovulatory phases than the luteal phase.

The decrease and increase in the hip abductors and adductors torque, maximum work, total work, and power coincide with the surging levels of the estradiol and progesterone during the menstrual phases. The effect of estradiol on the muscle force generation and the muscle contractile protein could explain the previous findings. The genomic effect of estradiol is mediated through nuclear alpha and beta estradiol receptors found in the muscles, which function as transcription factors once bound with their ligand. It was reported that estradiol enhances the strong bounding of the fraction of myosin heads to actin $[43,44]$ through enhancing ATPase activity [45] resulting in improving muscles contraction.

In addition, estradiol promotes glucose availability and uptake into type I muscle fibers providing the fuel of choice during short-duration exercise. High estradiol concentration in the luteal phase augments muscle glycogen storage capacity compared with a low estradiol environment of the early follicular phase. Moreover, estradiol reduces reliance on muscle glycogen during exercise and increases free fatty acid availability and oxidative capacity in exercise favoring endurance performance [30].

Previous studies conducted on rats have shown a difference between muscle fibers that are devoid and exposed to sex hormones. These studies suggested that the decreased ovarian hormones might lead to reduce fiber tension by decreasing the number of cross-bridges or the force per cross-bridges [43-46]. This indicates that the estradiol improves the intrinsic quality of skeletal muscles and their capacity to generate force [47].

Previous studies conducted on postmenopausal women support the findings of the present study. These studies have reported that decline in the estradiol due to menopause leads to reduced muscle strength in postmenopausal women, which is improved by administering hormonal replacement therapy [47].

St. Pierre-Schneider et al. [48] provided an evidence that estradiol is not the sole regulator of the muscle strength changes. They have reported that the maintenance of strength in women taking hormonal replacement therapy might be mediated by an interactive effect of progesterone and estradiol. In addition, Fouladi [49] have observed a high value of knee joint reposition error in the early follicular phase and an increase in the accuracy during the luteal phase with the elevated sex hormones' levels. They have supposed that elevated both hormones in the luteal phase are the reasons of increased knee joint position accuracy.

Despite of the increase in the peak torque and total work of the abductor and adductor muscles, the maximum work repetition number and work fatigue percentage did not change between the menstrual cycle phases. That means there are no changes in the maximum repetition number during which the greatest magnitude of torque generated [50] as well as, the work generated between the first and last thirds of the series of repetitions [51]. These findings suggest that the hormones variation during the menstrual cycle do not affect muscle performance consistency or the ability of muscles to maintain torque generation capacity [17].Acceleration time corresponds to the time needed to reach the predetermined velocity for the isokinetic test when starting from the rest position 
[52]. The results showed no change in the abductor and adductor muscles acceleration time, which indicates the maintenance of neuromuscular capacity to develop torque quickly as reported by van Cingel et al. [52] during phases of the menstrual cycles. In addition, the nonchange in the deceleration time suggests that the hormones variation do not affect the capacity of the females to maintain maximum abductors and adductors torques to the end of the tested range of motion at the required speed [17].

Also, the results have shown no difference in the angle of the abductors and adductors peak torques between the two menstrual cycle phases. This variable corresponds to the hip joint position at the moment of peak torque generation [53]. It is an important variable during muscle performance assessment. It is considered as an indicator of changes in optimal muscle length and the angle of insertion/lever arm during rotatory motion [54].

There are some limitations of the present study. First, the females' nutritional status and mood changes may affect the outcomes of this study. Second, the fluctuation of other hormones, such as relaxin and testosterone, may also influence tissue properties [55], so further research is warranted to investigate the impact of these hormones on hip muscles torques. Third, our data are limited to isokinetic hip muscles performance testing during the early follicular phase and mid-luteal phase. However, we did not investigate the effect of rise in estradiol concentration when progesterone is still low in mid-follicular phase. Therefore, further research is needed to examine the effect of hormones variation at different times of the menstrual cycles and using other measures of the neuromuscular function.

It can be concluded that abductor and adductor muscles performance changes in conjunction with the surging levels of estradiol and progesterone during normal menstrual cycle. Menstrual cycle phase needs to be considered when designing training programs for sedentary college students. Also, it is important to address the role of prevention strategies in decreasing the rate of injury during the early follicular phase among college students.

\section{Acknowledgements}

The authors acknowledge all college students who participated in this study for their cooperation.

\section{Financial support and sponsorship}

Nil.

\section{Conflicts of interest}

There are no conflicts of interest.

\section{References}

1 Cole LA, Ladner DG, Byrn FW. The normal variabilities of the menstrual cycle. Reprod Endocrinol 2009; 91:522-527.

2 Casey E, Hameed F, Dhaher Y. The muscle stretch reflex throughout the menstrual cycle. Med Sci Sports Exerc 2014; 46:600-609.

3 Herzberg SD, Motu'apuaka ML, Lambert W, Fu R, Brady J, Guise JM. The effect of menstrual cycle and contraceptives on ACL injuries and laxity: a systematic review and meta-analysis. Ortho J Sports Med 2017; 5:232596711771878.

4 Voskanian N. ACL injury prevention in female athletes: review of the literature and practical considerations in implementing an ACL prevention program. Curr Rev Musculoskelet Med 2013; 6:158-163.

5 Casteleyn PP, Handelberg F. Non-operative management of anterior cruciate ligament injuries in the general population. J. Bone Joint Surg $\mathrm{Br}$ 1996; 78:446-451.

6 Phillips SK, Sanderson AG, Birch K, Bruce SA, Woledge RC. Changes in maximal voluntary force of human adductor pollicis muscle during the menstrual cycle. J Physiol (Cambridge, UK) 1996; 496:551-557.

7 Sarwar R, Niclos BB, Rutherford OM. Changes in muscle strength, relaxation rate and fatigability during the human menstrual cycle. $\mathrm{J}$ Physiol (Cambridge, UK) 1996; 493:267-272.

8 Janse de Jonge XA, Boot CR, Thom JM, Ruell PA, Thompson MW. The influence of menstrual cycle phase on skeletal muscle contractile characteristics in humans. J Physiol (Cambridge, UK) 2001; 530:161-166.

9 Gur H. Concentric and eccentric isokinetic measurements in knee muscles during the menstrual cycle: A special reference to reciprocal moment ratios. Arch Phy Med Rehabil 1997; 78:501-505.

10 Lee SK, Lee SY, Jung JM. Muscle activity of the gluteus medius at different gait speeds. J Phys Ther Sci 2014; 26:1915-1917.

11 Belhaj K, Meftah S, Mahir L, Lmidmani F, Elfatimi A. Isokinetic imbalance of adductor-abductor hip muscles in professional soccer players with chronic adductor-related groin pain. Eur J Sport Sci 2016; 16:1-6.

12 Brent J, Myer GD, Ford KR, Paterno M, Hewett T. The effect of sex and age on isokinetic hip abduction torques. J Sport Rehabil 2012; 22:41-46.

13 Haines TL, McBride JM, Triplett NT, Skinner JW, Fairbrother KR, Kirby TJ. A comparison of men's and women's strength to body mass ratio and varus/valgus knee angle during jump landings. J Sport Sci 2011; 29:1435-1442.

14 Mitani Y. Gender-related differences in lower limb alignment, range of join motion, and the incidence of sports injuries in Japanese university athletes. J Phys Ther Sci 2017; 29:12-15.

15 Kagaya $Y$, Fujii Y, Nishizono H. Association between hip abductor function, rear-foot dynamic alignment, and dynamic knee valgus during single-leg squats and drop landings. J Sport Health Sci 2015; 4:182-187.

16 Palmer K, Hebron C, Williams JM. A randomised trial into the effect of an isolated hip abductor strengthening programme and a functional motor control programme on knee kinematics and hip muscle strength. BMC Musculoskelet Disord 2015; 16:105.

17 Amaral G, Marinho H, Ocarino J, Silva P, Souza T, Fonseca S. Muscular performance characterization in athletes: a new perspective on isokineticvariables. Braz J Phys Ther 2014; 18:521-529.

18 Cesar G, Pereira V, Santiago P, Benze B, da Costa P, Amorim C, et al. Variations in dynamic knee valgus and gluteus medius onset timing in nonathletic females related to hormonal changes during the menstrual cycle. Knee 2011; 18:224-230.

19 Su HW, Yi YC, Wei TY, Chang TC, Cheng CM. Detection of ovulation, a review of currently available methods. Bioeng Transl Med 2017; 2:238-246

20 Dedrick G, Sizer P, Merkle J, Hounshell T, Robert-McComb J, Sawyer S, et al. Effect of sex hormones on neuromuscular control patterns during landing. J. Electromyogr Kinesiol 2008; 18:68-78.

21 Stricker R, Eberhart R, Chevailler MC, Quinn FA, Bischof P, Stricker R. Establishment of detailed reference values for luteinizing hormone, follicle stimulating hormone, estradiol, and progesterone during different phases of the menstrual cycle on the Abbott ARCHITECT_analyzer. Clin Chem Lab Med 2006; 44:883-887.

22 Konopka C, Morais E, Naidon D, Pereira A, Rubin M, Oliveira J, et al. Maternal serum progesterone, estradiol and estriol levels in successful dinoprostone-induced labor. Braz J Med Biol Res 2013; 46:91-97. 
23 Karatrantou K, Paschalis V, Zafeiridis A, Katsareli E, Bilios P, Kellis S. Reliability of concentric and eccentric strength of hip abductor and adductor muscles in young soccer players. Biol Sport 2015; 32:351-356.

24 Boling M, Padua D, Creighton R. Concentric and eccentric torque of the hip musculature in individuals with and without patellofemoral pain. J Athl Training 2009; 44:7-13.

25 Bruyneel AV, Gafner SC, Ferrari S, Gold G, Monnin D, Terrier P, et al. Intrarater reliability of hip abductor isometric strength testing in a standing position in older fallers and non-fallers. Eur Rev Aging Phys Act 2018; 15:9.

26 Ling W, Chen F, McDonough A. Evaluation of the cushion setting on performance of a biodex II dynamometer. Arch Phys Med Rehabil 1999; 80:350-354

27 Montgomery M, Shultz S. Isometric knee-extension and knee-flexion torque production during early follicular and postovulatory phases in recreationally active women. J Athl Training 2010; 45:586-593.

28 Neill S, Maclean A, Farage M. Physiological changes during menstruation. Obstet Gynecol Surv 2009; 64:58-72.

29 Bambaeichi E, Relly T, Cable NT, Giacomoni M. The isolated and combined effects of menstrual cycle phase and time-of-day on muscle strength of eumenorrheic females. Chronobiol Int 2004; 21:499-514.

30 Oosthuyse $\mathrm{T}$, Bosch A. The effect of the menstrual cycle on exercise metabolism: implications for exercise performance in eumenorrhoeic women. J Sports Med 2010; 40:207-227.

31 Middleton LE, Wenger HA. Effects of menstrual phase on performance and recovery in intense intermittent activity. Eur J Appl Physiol 2006; 96:53-58.

32 Fridén $C$, Hirschberg A, Saartok T. Muscle strength and endurance do not significantly vary across 3 phases of the menstrual cycle in moderately active premenopausal women. Clin J Sport Med 2003; 13:238-241.

33 Quintino LF, Franco J, Gusmão AFM, Silva PFS, Faria CDCM. Trunk flexor and extensor muscle performance in chronic stroke patients: a case-control study. Braz J Phys Ther 2017; 22:231-237.

34 Geiser CF, O'Connor KM, Earl JE. Effects of isolated hip abductor fatigue on frontal plane knee mechanics. Med Sci Sports Exerc 2010; 42:535-545.

35 Powers $\mathrm{C}$. The influence of abnormal hip mechanics on knee injury: a biomechanical perspective. J. Orthop Sports Phys Ther 2010; 40:42-51.

36 Dierks TA, Manal KT, Hamill J, Davis IS. Proximal and distal influences on hip and knee kinematics in runners with patellofemoral pain during a prolonged run. J Orthop Sports Phys Ther 2008; 38:448-456.

37 Heinert BL, Kernozek TW, Greany JF, Fater DC. Hip abductor weakness and lower extremity kinematics during running. J Sport Rehabil 2008; 17:243-256.

38 Cashman G. The effect of weak hip abductors or external rotators on knee valgus kinematics in healthy subjects: a systematic review. J Sport Rehabil 2012; 21:273-284.

39 Lee S, Powers C. Fatigue of the hip abductors results in increased mediallateral center of pressure excursion and altered peroneus longus activation during a unipedal landing task. Clin Biomech 2013; 28:524-529.

40 Garrison J, Bothwell J, Cohen K, Conway J. Effects of hip strengthening on early outcomes following anterior cruciate ligament reconstruction. Int $\mathrm{J}$ Sports Phys Ther 2014; 9:157-167.
41 Arendt E, Bershadsky B, Agel J. Periodicity of noncontact anterior cruciate ligament injuries during the menstrual cycle. Gend Med 2002; 5:19-26.

42 Lefevre N, Bohu Y, Klouche S, Lecocq J, Herman S. Anterior cruciate ligament tear during the menstrual cycle in female recreational skiers. Orthop Traumatol Surg Res 2013; 99:571-575.

43 Moran AL, Warren GL, Lowe DA. Removal of ovarian hormones from mature mice detrimentally affects muscle contractile function and myosin structural distribution. J Appl Physiol 2006; 100: 548-559.

44 Moran AL, Nelson SA, Landisch RM, Warren GL, Lowe DA. Estradiol replacement reverses ovariectomy-induced muscle contractile and myosin dysfunction in mature female mice. J Appl Physiol 2007; 102:1387-1393.

45 Wattanapermpool J, Riabroy T, Preawnim S. Estrogen supplement prevents the calcium hypersensitivity of cardiac myofilaments in ovariectomized rats. Life Sci 2000; 66:533-543.

46 Moran AM, Warren GL, Lowe DA. Estradiol's beneficial effect on murine muscle function is independent of muscle activity. J Appl Physiol 2011; 110:109-115.

47 Greising SM, Baltgalvis KA, Lowe DA, Warren GL. Hormone therapy and skeletal muscle strength: a meta-analysis. J Gerontol A Biol Sci Med Sci 2009; 64A:1071-1081.

48 St. Pierre-Schneider B, Fine JP, Nadolski T, Tiidus PM. The effects of estradiol and progesterone on plantarflexor muscle fatigue in ovariectomized mice. Biol Res Nurs 2004; 5:265-275.

49 Fouladi R. Sex hormones and neuromuscular control system. In: Dubey P, (ed). Sex hormones. Croatia: InTech; 2012;263-277.

50 Arrigo CA, Wilk KE, Andrews IR, James R. Peak torque and maximum work repetition during isokinetic testing of the shoulder internal and external rotators. Isokinet Exerc Sci 1994; 4:171-175.

51 Silva JP, Pereira DS, Coelho FM, Lustosa LP, Dias JM, Pereira LS. Clinical, functional and inflammatory factors associated with muscle fatigue and self-perceived fatigue in elderly community-dwelling women. Rev Bras Fisioter 2011; 15:241-248.

52 van Cingel RE, Kleinrensink G, Uitterlinden EJ, Rooijens PPGM, Mulder $\mathrm{PGH}$, Aufdemkampe $\mathrm{G}$, et al. Repeated ankle sprains and delayed neuromuscular response: acceleration time parameters. J Orthop Sports Phys Ther 2006; 36:72-79.

53 Cramer JT, Housh TJ, Johnson GO, Weir JP, Beck TW, Coburn JW. An acute bout of static stretching does not affect maximal eccentric isokinetic peak torque, the joint angle at peak torque, mean power, electromyography, or mechanomyography. J Orthop Sports Phys Ther 2007; 37:130-139.

54 Brughelli M, Cronin J, Nosaka K. Muscle architecture and optimum angle of the knee flexors and extensors: a comparison between cyclists and Australian Rules football players. J Strength Cond Res 2010; 24:717-721.

55 Zazulak BT, Paterno M, Myer GD, Romani WA, Hewett TE. The effects of the menstrual cycle on anterior knee laxity. A systematic review. Sports Med 2006; 36:847-862. 